\title{
Narrativas de uma professora de um curso de Licenciatura em Música: entrelaçando memórias e práticas musicais
}

MARIA CECILIA DE ARAUJO RODRIGUES TORRES

Maria Cecilia de Araujo Rodrigues Torres é mestre em Educação pela PUCRS e doutora em Educação pela UFRGS. Atuou por mais de 20 anos como professora de música em Escolas de Educação Básica. Desde 2008 é docente do Curso de Licenciatura em Música do Centro Universitário Metodista/IPA. Atuou como professora por mais de 10 anos em cursos de formação continuada em música no Programa Descubra a Orquestra da Fundação OSESP/SP e foi Coordenadora da área da Música e Institucional do Projeto PIBID/CAPES/IPA. É pesquisadora desde 1996 do Grupo Educação Musical e Cotidiano do PPG/Música UFRGS (CNPq), sob a coordenação da profa. Dra. Jusamara Souza e também é pesquisadora convidada do Grupo de Pesquisa NARRAMUS da UFSM (CNPq), trabalhando com pesquisa (auto)biográfica. (http://lattes.cnpq.br/7834920626343641>).

AFILIAÇÃO: Centro Universitário Metodista IPA, Porto Alegre, Rio Grande do Sul. 


\section{- RESUMO}

Nos limites deste texto, trago um resumo de algumas reflexões sobra a minha aproximação e inserção como pesquisadora no campo dos estudos biográficos e das narrativas de si, entrelaçados com a educação musical e, desta forma, compartilho algumas narrativas autobiográficas como docente de um Curso de Graduação em Música/Licenciatura, no período entre 2008 e 2018. Rememoro questões que emergiram ao final da minha tese de doutorado no ano de 2003, na perspectiva de uma pesquisa no campo das autobiografias de si e memórias, e, desta maneira, busco entrelaçar narrativas diversas de discentes do curso em diferentes disciplinas e atividades tais como Projeto PIBID e Estágios Supervisionados em espaços não escolares no decorrer destes dez anos. Assumo assim o papel e a responsabilidade de narradora destas narrativas e memórias, em um diálogo com autores dos campos dos estudos autobiográficos/ narrativas e da educação musical, que realizam pesquisas neste campo teórico. Finalizo pontuando que este exercício de recontar e rememorar me constituem a cada dia como professora formadora/pesquisadora da área da Educação Musical.

\section{PALAVRAS-CHAVE}

Narrativas de si, memórias, pesquisa (auto)biográfica, Licenciatura em Música

\section{ABSTRACT}

In the boundaries limits of this abstract I present some reflections of my forthcoming and insertion as researcher of the field of biographic studies interlaced with music education and in such way i share some autobiographic narratives as a professor of an university graduation course of Music in the period understood between 2008 and 2018. To date, there are questions that emerged at the end of my PhD thesis finished in the year of 2003, in the perspective of the field of autobiographies and self memories and I cross different narratives of the students of the course in many classes and activities as the Project PIBID and Supervised Internship classes in nonschool spaces along these ten years. I assume the responsibility of storyteller of these narratives and memories in a dialogue with authors of the field of autobiographic narratives and music education that research in this theoretical field. Finally, i punctuate that such exercise of cutting and recalling constitute me everyday as a researcher in the area of Music Education.

\section{KEYWORDS}

Self narratives, Autobiographic research, Music Graduation Course 


\section{Abertura: como começou esta história de pesquisar narrativas de si}

Início esta escrita narrativa (auto)biográfica impregnada de lembranças e histórias no sentido de situar os leitores neste espaço biográfico e, assim sendo, trago as palavras de Frison e Veiga Simão (2011), quando as autoras ressaltam que "o processo de escrita narrativa remete à compreensão de que o aprendiz de professor é ator e autor, investindo em sua interioridade e no conhecimento de si, pois, ao se questionar sobre sua identidade, reflete sobre ela e forma-se" (FRISON e VEIGA SIMÃO, 2011, p.205). Assim, essas narrativas são de uma autora que vai compondo estas cenas no espaço (auto)biográfico).

Os primeiros passos rumo ao campo de pesquisa dos estudos (auto)biográficos aconteceram na época da minha aprovação na seleção de doutorado para o Programa de Pós-Graduação em Educação da Universidade Federal do Rio Grande do Sul, em agosto de 1999, com a apresentação de um Projeto de pesquisa que tinha como objetivo conhecer quais eram as memórias musicais através das narrativas orais e escritas de vinte mulheres, todas elas alunas de um Curso de Pedagogia de uma Universidade na cidade de Porto Alegre. A partir deste momento, eu estava comprometida com as leituras e autores, com dúvidas e descobertas que iriam desvelar as narrativas das lembranças musicais, imbricadas com as identidades musicais deste grupo.

Descobertas e estranhamentos, sim, pois eu havia realizado e concluído meu mestrado em Educação no ano de 1995 com o tema: O processo de musicalização de adultos: sentimentos e motivações e tinha pesquisado na perspectiva da Fenomenologia, com leituras de autores e filósofos como Maurice Merleau-Ponty e Agnes Heller, dentre outros, e com o uso da entrevista fenomenológica, seguida da análise dos dados para o desvelamentos das essências. Era um paradigma de pesquisa que, ao longo dos dois anos do mestrado, fui conhecendo, sempre tentando me aproximar dos fundamentos da Fenomenologia da Percepção, em um processo de reaprender e desvelar questões que faziam parte das motivações de doze adultos, de diferentes profissões, que buscavam a musicalização no momento da vida adulta. Foi uma temática que me acompanhou durante os mais de vinte anos como educadora musical em escolas da educação básica, e que, neste momento do mestrado, emergiu em questões que foram delineando meu tema e campo de pesquisa.

Finalizando as narrativas relacionadas ao mestrado, retorno ao campo das narrativas (auto)biográficas e a aproximação deste método com a linha dos Estudos Culturais em Educação, linha na qual eu cursei disciplinas e fiz minha primeira aproximação com autores que trabalham com memórias e narrativas como Jorge Larrosa, Leonor Arfuch, Beatriz Sarlo, Antonio Nóvoa e Mathias Finger (2010), dentre outros.

Na perspectiva de Nóvoa e Finger, na obra "O método (auto)biográfico e a formação" (2010), os autores chamam a atenção para o fato de que

O método biográfico ${ }^{1}$ permite que seja concedida uma atenção muito particular e um grande respeito pelos processos das pessoas que se formam: nisso reside uma das principais qualidades, que o distinguem, aliás, da maior parte das outras metodologias de investigação em ciências sociais (NÓVOA; FINGER, 2010, p.22).

\footnotetext{
$\overline{1}$ Grifo da autora
}

ouvirouver Uberlândia v. 15 n. 1 p. 72-84 jan. |jun. 2019 
No final do ano de 2000, já havia cumprido os créditos do doutorado e estava com o Projeto de Qualificação em andamento e esboçado. Nesta etapa, apliquei para uma bolsa sandwich doutorado (CAPES/PDEE) na University of Queensland/School of Education, sob a orientação do prof. Dr. Allan Luke, para ficar lá durante sete meses estudando e discutindo meu projeto na perspectiva das narrativas e discursos. Em janeiro de 2001 embarquei para este período na Austrália e ressalto nas minhas narrativas (auto)biográficas que esta era a minha estreia de um período único, o primeiro em minha vida adulta em que ficaria só estudando, lendo e organizando meu Projeto de Qualificação de tese, com direito a assistir algumas disciplinas ministradas pelo Professor Luke e também participar do grupo de estudos coordenado por sua esposa, a prof. Dra. Carmen Luke.

Foram meses de muitas aprendizagens, descobertas, conquistas; de fazer laços com colegas e amigos de pesquisa, de ter algum estranhamento com a língua inglesa e o sotaque australiano; mas, ao mesmo tempo, foram momentos quase mágicos em que tive oportunidade de discutir sobre temas das teses dos colegas, de participar de aulas e seminários, de organizar "almoços étnicos" com os colegas e de poder conhecer sobre as culturas diversas dos colegas vindos da Índia, Hong Kong, Cingapura, Grécia, Ilhas Solomon, Estados Unidos, dentre outros, já que eu era a primeira brasileira que ia para a School of Education/UQ em um programa de bolsas PDEE/CAPES. Este período me possibilitou, de maneira diferenciada, poder exercitar e lembrar das minhas memórias e narrativas que me constituíram como professora de música ao longo de quase 25 anos.

Aprendi que havia necessidade de eu pensar na minha própria história e escrever fragmentos de minhas memórias musicais para então, poder ouvir as histórias dos outros. Narrar-me primeiro para depois tornar-me narradora, em um processo contínuo de contar-me e recontar-me e, como nos lembra Delory-Momberger "é a narrativa que faz de nós o próprio personagem de nossa vida; é ela, enfim, que dá uma história a nossa vida: não fazemos a narrativa de nossa vida porque temos uma história; temos uma história porque fazemos a narrativa de nossa vida". (DELORY-MOMBERGER, 2008, p. 37).

\section{Narrativas de si no delineamento do Projeto de tese}

Em uma das orientações com o professor Allan Luke, quando estava delineando os caminhos metodológicos dos sujeitos da pesquisa para compor o projeto, ele sugeriu que eu escrevesse sobre minhas memórias musicais antes de começar a pensar o que iria perguntar para as participantes da minha pesquisa. la rememorar e escrever fragmentos de minhas memórias musicais e compartilhar estas narrativas de si também na pesquisa. Foi preciso lembrar e voltar no tempo, trazendo sonoridades, imagens e locais que formavam essa teia de memórias, como este excerto que trago da minha tese: 
Recordo das minhas primeiras aulas de violino, com dez anos de idade, ansiosa por tocar no instrumento e ao mesmo tempo encantada com a sonoridade e a leveza do toque da minha professora ao dediIhar as cordas e demonstrar golpes de arcadas... Guardei em minha memória, durante décadas, a lembrança e imagem de suas mãos, com dedos longos executando melodias com precisão e técnica. Era um exemplo que queria imitar... (TORRES, 2003, p78).

A organização e escrita final do Projeto de qualificação da tese aconteceu entre os meses de janeiro e dezembro de 2001, com uma pré-defesa para o grupo de pesquisa de colegas na University of Queensland/School of Education e professores, em agosto de 2001. Voltei ao Brasil no final de agosto de 2001 e defendi o projeto de qualificação da tese em dezembro, com muita vontade de iniciar as entrevistas com as narrativas de si e de ir a campo. Entre o meu retorno e a defesa final da tese em dezembro de 2003, foram muitas as descobertas deste espaço biográfico como os desafios de trabalhar com essa abordagem de pesquisa trazia, desde realizar entrevistas narrativas, até adentrar no estudo das "narrativas de si" e também pelo fato de ser uma abordagem considerada nova em pesquisa, tanto para a área dos Estudos Culturais em Educação como para a Educação Musical.

Entre questionamentos e dúvidas, leituras, escritas e reescritas, entrevistas, análises, trilhas sonoras e muitas narrativas, a tese de doutorado foi sendo construída como um mosaico no qual fui pesquisar e conhecer termos e conceitos como biografias, autobiografias, confissões, memórias, narrativas de si, diários íntimos, dentre outros, que nas palavras de Arfuch (2002) fazem parte "desta obsessão de deixar marcas, rastros, inscrições, desta ênfase na singularidade que é a busca da transcendência" (ARFUCH, 2002, p.17).

Passeggi e Souza (2017), em artigo intitulado "O Movimento (Auto)Biográfico no Brasil: Esboço de suas Configurações no Campo Educacional" apontam que as pesquisas (auto)biográficas já estavam sendo desenvolvidas na área da Educação. Eles enfatizam "dois momentos que se configuram como marcos do movimento (auto)biográfico em educação, no Brasil: sua emergência, nos anos 1990, e sua diversificação a partir dos anos 2000" (p.9). Os autores prosseguem em suas reflexões e chamam a atenção para este espaço como campo de pesquisa e, portanto,

cabe nos perguntar sobre que tipo de conhecimento é possível gerar com base nessas narrativas de si e qual é a sua relevância para a investigação científica no que concerne os conhecimentos humanos e sociais. Situada no âmbito da pesquisa qualitativa, a pesquisa (auto) biográfica em Educação tem procurado superar o dilema que lhe é imposto: ou acomodar-se aos padrões existentes do conhecimento dito científico ou, ciente da especificidade epistemológica do conhecimento que ela produz, contribuir para a construção de novas formas de se conceber a pessoa humana e os meios de pesquisa sobre ela e com ela (PASSEGGI e SOUZA, 2017, p.9). 
Antes de passar para o tópico com narrativas que me constituíram como docente em um Curso de Graduação/Licenciatura em música desde 2008 e as quais socializo nas fronteiras deste artigo, narro um fato que considero importante para a continuidade dos meus trabalhos e interesse por este campo de pesquisa qual seja a minha participação no 1‥ CIPA (Congresso Internacional de Pesquisa Autobiográfica), no ano de 2004 na cidade de Porto Alegre e no qual tive a oportunidade de apresentar um recorte da minha tese e ouvir e conhecer ao vivo vários dos autores lidos e referendados na pesquisa.

\section{Narrativas iniciais de uma docente de um curso superior de música}

Ao iniciar a escrita das minhas narrativas como docente no ensino superior, situo que a minha primeira experiências neste segmento foi em 1997, em um curso de Graduação em Pedagogia, ministrando um componente de música. A partir de 2003, assumi como docente em cursos de Música/Licenciatura e faço uma ressalva que, neste artigo, trago um recorte dos anos de 2008 a 2018 com algumas narrativas docente, em uma interlocução dos estudos (auto)biográficos com a educação musical. Assim, mesclo memórias e experiências que foram sendo rememoradas e entrelaçadas ao longo destes últimos dez anos, no qual tenho atuado como docente em um curso de Licenciatura em Música na cidade de Porto Alegre. Neste espaço, assumi papéis diversos, ora ministrando diferentes disciplinas práticas e teóricas, ora assumindo a coordenação do Curso, atuando como coordenadora de área e institucional do Programa PIBID/CAPES, ou trabalhando em projetos de extensão, coordenando estágios supervisionados no espaço de um hospital ou como professora/coordenadora de um Grupo de Estudos.

Este exercício de narrar e rememorar foi sendo construído a partir de leituras que fiz e autores que conheci e com os quais fui me identificando, tais como Mariana Luz de Barros (2016) no que diz respeito aos movimentos que envolvem memórias e modos de existência, no qual a autora comenta que

\footnotetext{
Nos gêneros autobiográficos, é a escritura que possibilita a passagem das lembranças, sob o modo atualizado, à realização. A narrativa das memórias faz com que o esquecido seja atualizado por meio da lembrança e se realize "novamente" ao ser textualizado. É esta direção, da ausência para a presença, que diz respeito à rememoração, que pode atingir aquele que se lembra com diversos graus de impacto (BARROS, 2016, p.59).
}

Ainda no que tange ao campo de narrativas de si e suas interlocuções com a identidade docente e suas memórias, pensar neste desejo ou necessidade de escrever sobre as próprias experiências docentes já era uma temática que me acompanhava faz tempo, e que, agora, no início de 2019, vou tecendo com fragmentos de minha docência/formação. Trago algumas ideias de Araujo (2016), que analisa as narrativas docentes impregnadas de práticas e saberes e ressalta que "nossa trajetória com a formação docente tem nos ensinado que o movimento de reconhecer-se como professora pesquisadora que indaga, busca, busca, reflete sobre a própria 
prática se amplia". A autora evidencia, ainda, que essa prática "se adensa, se corporifica na escrita docente" (p.44). A citada autora complementa suas reflexões em relação ao escrever docente, pontuando que "não se trata apenas de refletir sobre a prática, mas de se valer da produção escrita como espaço para essa reflexão, em outras palavras, reconhecer-se como professora pesquisadora também implica traçar as próprias linhas... (p.44).

A seguir, passo a narrar cenas que aconteceram ao longo destes dez anos, nas quais as memórias e narrativas autobiográficas dos alunos foram conhecidas, desveladas e socializadas em múltiplos contextos do curso e nas quais não existiu a preocupação por parte desta professora e narradora deste texto em trazer uma narrativa linear ou cronológica. Em vários momentos desta narrativa as memórias dos alunos são polifônicas e se entrelaçam com as minhas e ressoam no meu modo de narrar, com diferentes dinâmicas e movimentos.

\title{
3. Rememorando
}

Cabe lembrar que neste artigo não tenho como objetivo trazer a "história da minha vida" como docente universitária, com personagens e enredos fixos e nem de listar fatos através de narrativas, mas sim de continuar a exercitar a escrita de si e, desta maneira, poder rememorar e refletir sobre minhas concepções, aprendizados, práticas musicais com diferentes personagens e enredos que me ajudam a tecer o mundo vivido.

\begin{abstract}
A narrativa transforma os acontecimentos, as ações e as pessoas do vivido em episódios, em enredos e em personagens; ordena os acontecimentos no tempo e constrói entre eles relações de causas, de consequências, de fim, dando, assim, um lugar e um sentido ao ocasional, ao fortuito, ao heterogêneo. Pela narrativa, os homens tornamse os próprios personagens de suas vidas e dão a elas uma história [...] o narrativo é o lugar onde a existência humana toma forma, onde ela se elabora e se experimenta sob a forma de uma história (DELORYMOMBERGER, 2012, p.39-40).
\end{abstract}

A partir destes acontecimentos e ações ressaltados por Delory-Momberger (2012), situo alguns dos espaços nos quais tive a oportunidade e trabalhar com as narrativas autobiográficas dos alunos neste curso de música e, assim, inicio por algumas disciplinas que ministrei e que em determinados momentos eu apresentava essa abordagem e trabalhava com as narrativas de si. Trabalhar com a elaboração e defesa de um projeto de pesquisa no último semestre do curso tem sido um dos desafios neste componente curricular que ministrei nestes dez anos e com o/no qual venho aprendendo muito e me ressignificando como docente. Com o trabalho de elaboração e estruturação de um projeto de pesquisa, vou entrelaçando leituras, escritos semanais e organização das etapas do projeto, em uma interlocução constante com o tema de pesquisa que cada um elege para compor o seu projeto. Sendo assim os alunos mesclam narrativas orais e escritas com os exercícios de escreverem resumos científicos, narrativas de si, cartas apresentando seu projeto e 
relatos de experiências, possibilitando assim que falem sobre seu tema e seu problema/questão de pesquisa e assim compartilhem suas ideias e inquietações.

\subsection{Temas de pesquisas: narrativas entrelaçadas}

Ao retomar aos temas de pesquisa que foram sendo delineados e que são amalgamados com as vivências e histórias dos alunos, fui desvelando narrativas orais e escritas que iam justificando com pertinência as escolhas destas temáticas para um projeto de pesquisa em educação musical, ora compondo o tópico das justificativas, ora tecendo os fios do exercício da escolha e das relações do pesquisador com seu tema. Em alguns momentos, fizemos o exercício de "juntar pedacinhos" a partir do trabalho de Dias (2008), com a proposta de fazerem uma narrativa escrita em duplas sobre questões da disciplina. Já em outras aulas trouxe a leitura de excertos de textos que apresentavam o campo da pesquisa (auto)biográfica como o de Carvalho (2010) e que convidava os acadêmicos a escreverem uma breve (auto)biografia musical que poderiam inserir nos seus Relatórios de Conclusão de Curso (RCC), tanto no capítulo da Introdução quanto nas reflexões finais. Esta atividade oportunizou que as temáticas como que emergiram a cada semestre mostrassem traços (auto)biográficos dos acadêmicos como, por exemplo, relacionadas ao processo de criação/composição musical, ou às práticas vocais e instrumentais, ou nos espaços das escolas específicas de música, em oficinas de choro ou de maracatu, ou ainda com corais de idosos, em escolas específicas de música, escolas da educação básica, musicalização de bebes ou no contexto da música no hospital, dentre muitos outros.

Quando rememoro e narro este processo como docente no exercício de realizar estas práticas de escrever e narrar oralmente com acadêmico deste curso de graduação em música, acredito que este seja um dos focos dos trabalhos que estão sendo realizados na área da educação musical no campo das pesquisas (auto)biográficas na última década. Corroborando com esta ideia, trago um excerto de Maffioletti e Abrahão (2016, p.43) em artigo no qual as autoras salientam que "a pesquisa narrativa em educação musical está em andamento no cenário brasileiro, tanto na área da Educação quanto na área da Música, com produção científica que envolve (auto)biografias, memórias, histórias de vida e práticas de formação".

Embora o objetivo deste artigo não seja de fazer um levantamento das pesquisas da educação musical no Brasil que trabalham nesta perspectiva das narrativas de si e (auto)biografias, cito alguns destes trabalhos tais como o de Louro e Torres (2003), Louro (2004), Louro, Teixeira e Reck (2016), Abreu (2011, 2017), Lima (2013), Pedrini (2013) Anders (2014), Maffioletti e Abrahão (2016, 2017), Garbosa (2016), Gaulke (2013), Reck (2017), Almeida (2019), dentre vários outros que não foram aqui mencionados e os quais tive a oportunidade de ler, de participar como pesquisadora convidada do Grupo de Pesquisa Narramus (CNPq/UFSM), de conhecer nas apresentações do CIPA (Congresso Internacional de Pesquisa (Auto)biográfica) ou de integrar bancas de mestrado ou doutorado. Sendo assim, selecionei um excerto do artigo de Abreu (2017) intitulado "História de vida e sua representatividade no campo da educação musical: um estudo com dois Educadores Musicais do Distrito Federal”, no qual a autora evidencia que a História de vida possibilita "entender como um sujeito chega a ser o que é" (p.209), acrescentando que 
O conhecimento que se faz pelas narrativas de si torna sua própria história um objeto de investigação, extraindo saberes para si e para o outro, fazendo o registro dessa construção histórica para evidenciar acontecimentos que o formaram nos contextos históricos, sociais, culturais e, neste caso, músico-educacionais (ABREU, 2017, p.209).

A partir das reflexões de Maffioletti e Abrahão (2016) sobre o cenário da pesquisa (auto)biográfica no Brasil, encerro esta seção comentando que a área da educação musical vem construindo e ampliando sua história neste campo biográfico, com pesquisas detalhadas ao mesmo tempo densas em discussões teóricas e com temáticas das mais diversas, tanto em nível de mestrado, doutorado quanto pós-doutorado.

\subsection{Narrativas que soam e ecoam: Programa PIBID e Projeto Música no hospital}

As metodologias pautadas no método biográfico têm como foco as investigações como fontes pessoais, registrando experiências, acontecimentos e situações, de modo a compreender percursos pessoais e profissionais, construção e identidades. Assim, um dos elementos centrais do método biográfico é a memória (GARBOSA, 2016, p.77).

Entre os sons e memórias do PIBID (Programa de Iniciação à Docência) e do Projeto música no hospital (Estágio Supervisionado em espaços não escolares), escolho fazer a abertura deste subcapítulo com um excerto de Garbosa (2016), em pesquisa com bolsistas do PIBID-Música da UFSM e no qual ela apresenta e analisa narrativas orais e escritas produzidas por professores, bolsistas e um ex-bolsistas de iniciação à docência.

Ao rememorar as narrativas (auto)biográficas dos meus alunos, estes campos ou espaços foram lembrados como produtores de narrativas de si que ecoaram para além dos espaços de atuação pedagógico musical, como no caso das escolas parceiras para o PIBID, no qual discentes do curso participaram como bolsistas entre 2012/2 e 2017/2, e que durante estes anos atuaram em diferentes escolas Estaduais da cidade de Porto Alegre, com suas práticas musicais compartilhadas, desafios e aprendizagens. Neste Programa, realizaram muitas atividades em grupo e, em alguns momentos, faziam o exercício de organizarem e socializarem narrativas orais e escritas, como nos relatórios mensais individuais, nas oficinas de escrita e resumos coletivos, nos escritos individuais sobre os perfis dos alunos das escolas e no exercício da escrita coletiva de artigos (Torres, 2016). Havia também o espaço nas reuniões com os supervisores das escolas, nas reuniões com as coordenadoras de área e com a coordenação institucional em que os grupos de alunos traziam suas narrativas das práticas musicais e pedagógicas nas escolas. Um dos meus objetivos foi trabalhar entre o coletivo e o individual, entre o público e o privado, no sentido de os acadêmicos narrarem suas experiências profissionais/pessoais no âmbito do PIBID como no encerramento do Programa na Instituição, em que pedi aos bolsistas que trouxessem lembranças em forma de narrativas escritas com o tí- 
tulo "Histórias do PIBID" para formarmos um portfólio de memórias. Ao finalizar essas breves reflexões como docente e coordenadora da área da música por quase cinco anos, tive a oportunidade de trabalhar coletivamente com colegas de outros subprojetos nos espaços dos seminários institucionais, eventos da área da educação musical e de outras áreas, e, assim sendo, acredito que

[...] este foi um trabalho de juntar fios, de tecer narrativas de si e entrelaçar em narrativas de "nós", de mesclar ideias, de desacomodar verdades, e, acima de tudo, de promover através do exercício que cada um de nós realizou de narrar-se, seja individualmente ou coletivamente, ora por escrito em textos, resumos, ora oralmente em aulas, reuniões e apresentações em eventos científicos, no processo contínuo de tornar-se docente (TORRES, 2016, p.114).

O Projeto música no hospital é uma atividade que foi se construindo ao longo destes 10 anos, configurando-se como um dos espaços para a realização da III etapa dos Estágios supervisionados do curso, sempre com práticas musicais coletivas e que tem sido um lócus para muitas narrativas de si, tanto orais como escritas a partir das reflexões dos estagiários nos seus relatórios, com as escolhas musicais e o repertório com os pedidos dos pacientes e familiares, a escuta das conversas sussurradas, as sonoridades que invadem quartos, corredores, a mistura de sons de carrinhos de comida com macas e equipamentos pelos corredores e quartos, misturados aos sons dos instrumentos musicais com as vozes dos funcionários, pacientes e familiares. Pude perceber estas narrativas impressas nos títulos de alguns relatórios de estágio, assim como nas cenas que os alunos descrevem e analisam, com uma riqueza e diversidade de narrativas de si que ecoam em mim como docente neste espaço repleto de surpresas, aprendizagens, emoções, melodias e vozes. Não foi meu objetivo aqui trazer muitos dados e detalhar este projeto, mas sim contar um pouco deste espaço do hospital, que é único a cada dia com uma mescla do efêmero e denso, profundo, da noção de um tempo que pode ficar suspenso e, parafraseando Almeida (2019) no título de sua tese, um local de "produção de sentidos em meio à teia da vida"

\section{Finalizando}

Assim como foi difícil iniciar e ir tramando as narrativas para este artigo com o intuito de não fugir do título proposto, para o qual retornei algumas vezes para ler, reler ou mudar, fazer esta finalização também não foi fácil, na medida em que, cada vez que parava a escrita e retomava a leitura das narrativas escritas, muitos outros fios de memórias vinham, muitas vezes em turbilhões, misturando o vivido ao narrado. Sem dúvida, muitas narrativas ficaram mescladas, outras tantas foram interrompidas por mim como narradora deste texto, outras ficaram de fora. Retorno à minha proposta inicial de tramar algumas narrativas no sentido de compor este texto, sem nenhuma pretensão de esgotar assuntos, mas muito mais como uma oportunidade desta docente narrar fatos e cenas que foram compondo sua caminhada neste curso. 
Faço ainda algumas considerações finais relacionadas ao campo das pesquisas (auto)biográficas e não posso deixar de revelar o quanto este olhar metodológico foi fazendo parte do meu processo de constituição como docente neste curso, me desafiando a ter uma escuta mais atenta, um olhar aguçado e uma percepção impregnada de sensibilidade para tentar captar nas frestas do cotidiano essas narrativas, em uma trama com as leituras, discussões, trabalhos e com o olhar de pesquisadora que fui aprendendo e exercitando nos últimos de vinte e um anos a partir da convivência com a Professora Dra. Jusamara Souza, coordenadora do Grupo de Pesquisa EMCO (CNPq/PPGMúsica) da UFRGS) e com os colegas integrantes do EMCO. Assim encerro essas breves narrativas de uma docente que aprende a ser "autora" que continua a adentrar neste espaço biográfico.

\section{REFERÊNCIAS}

ABREU, Delmary Vasconcelos. Tornar-se professor de Música na educação básica. Tese (Doutorado em Música), Programa de Pós-Graduação em Música/UFRGS, 2011.

ABREU, Delmary Vasconcelos. História de vida e sua representatividade no campo da educação musical: um estudo com dois Educadores Musicais do Distrito Federal. InterMeio: Revista do Programa de PósGraduação em Educação, Campo Grande, MS, v. 23, n. 45, jan./jun. 2017.

ALMEIDA, Jéssica. Biografia Músico-Educativa: Produção de sentidos em meio à teia da vida. Tese (Doutorado em Educação), Programa de Pós-Graduação em Educação, Universidade Federal de Santa Maria, 2019.

ANDERS, Fernanda. Dançar na aula de música: Dá gosto de vir para o colégio. Porto Alegre, Programa de Pós-graduação em Educação - Dissertação (Mestrado em Educação), UFRGS. Porto Alegre, 2014.

ARAUJO, Mairce da Silva. Narrativas docentes: saberes, práticas, significações. In: MONTEIRO, Filomena de Arruda, NACARATO, Adair Mendes, FONTURA, Helena Amaral (Org.). Narrativas docentes, memórias e formação. Curitiba: CRV, 2016.

BARROS, Mariana Luz Pessoa. Lembrar, esquecer, memorizar: memória e modos de existência. Galaxia (São Paulo, online),n. 33, set.-dez, 2016.

CARVALHO, Maria Rosa Martins. Leitura e escrita como espaços autobiográficos de formação. São Paulo: Cultura Acadêmica/Editora UNESP, 2010.

DELORY-MOMBERGER, Christine. Biografia e educação: figuras do indivíduo-projeto. Tradução de Maria da Conceição Passegi, João G. da Silva Neto, Luis Passegi. São Paulo: Paulus; Natal: EDUFRN, 2008.

DELORY-MOMBERGER, Christine. A condição biográfica - ensaio sobre a narrativa de si na modernidade avançada. Natal: Editora da UFRN, 2012. 
DIAS, Cleuza Maria Sobral. Narrativas em processos de pesquisa e formação: escrevendo... juntando pedacinhos, reconstruindo trajetórias. In: Pesquisa (auto) biográfica: cotidiano, imaginário e memória. Natal: Editora da EDUFRN, 2008.

FRISON, Lourdes Maria Bragagnolo, VEIGA SIMÃO, Ana Margarida. Abordagem (auto)biográfica - narrativas de formação e de autorregulação da aprendizagem reveladas em portfólios reflexivos. In: Educação, Porto Alegre, v. 34, n. 2, p. 198-206, maio/ago. 2011.

GARBOSA, Luciane Wilke Freitas. Narrativas (auto)biográficas e formação docente: o PIBID como dispositivo grupal na formação de professores de música. In: VICENTINI, Paula Perin, CUNHA, Jorge Luiz da, CARDOSO, Lilian Auxiliadora Maciel (Org.). Experiências formativas e práticas de iniciação à docência. Curitiba: Editora CRV, 2016.

GAULKE, Tamar Genz. Aprendizagem da docência: um estudo a partir de narrativas de professores de música da educação básica. Dissertação (Mestrado em Música) - Porto Alegre, UFRGS, 2013.LIMA, Janaína Machado Asseburg. Ingeburg Hasenack: memórias de uma educadora musical. Dissertação (Mestrado em Educação), Programa de Pós-Graduação em Educação/UFSM, 2013.

LOURO, Ana Lúcia; TORRES, Maria Cecilia. A música nossa de cada dia: narrativas de si e crenças pedagógicas. ANAIS do XIII Encontro Nacional da ABEM, Florianópolis, 2003.

LOURO, Ana Lúcia de Marques. Ser docente universitário-professor de música: dialogando sobre identidades profissionais com professores de instrumento. Tese (Doutorado em Música), Programa de PósGraduação em Música/UFRGS, 2004.

LOURO, Ana Lúcia Louro, TEIXEIRA, Ziliane Lima de Oliveira, RECK, André Müller. Pesquisa em Música: Reflexões sobre memórias musicais e dimensões da "experiência de si". Revista Digital do LAV - Santa Maria - vol. 9, n. 1, p. 89 - 102. - jan./abr, 2016.

MAFFIOLETTI, Leda de Albuquerque, ABRAHÃO, Maria Helena. Significações acerca de si mesmo por meio de narrativas sobre experiência musical. Currículo sem Fronteiras, v. 16, n. 1, p. 42-58, jan./abr. 2016.

MAFFIOLETTI, Leda de Albuquerque, ABRAHÃO, Maria Helena. Conhecimentos produzidos a partir da Pesquisa Narrativa em Educação Musical. In: Atas CIAIQ2017. Investigação Qualitativa em Educação//Investigación Cualitativa en Educación//Volume 1, 2017.

NÓVOA, Antonio, FINGER, Matthias. O método (auto)biográfico e a formação. Natal: EDUFRN, 2010.

PASSEGGI, Maria da Conceição, SOUZA, Elizeu Clementino. O Movimento (Auto)Biográfico no Brasil: Esboço de suas Configurações no Campo Educacional. Investigación Cualitativa 2(1), 2016.

PEDRINI, Juliana. Sobre Aprendizagem Musical: um estudo de narrativas de crianças. Dissertação (Mestrado em Música), Programa de Pós-Graduação em Música /Universidade Federal do Rio Grande do Sul, 2013. 
RECK, André Müller. Narrativas religiosas no ensino superior em música: uma abordagem narrativas (auto)biográfica. Tese (Doutorado em Educação), Programa de Pós-Graduação em Música/UFSM, 2017.

TORRES, Maria Cecilia de Araujo Rodrigues. Identidades musicais de alunas da Pedagogia: músicas, memórias e mídia. Tese (Doutorado em Educação), Programa de Pós-Graduação em Educação/UFRGS, 2003.

TORRES, Maria Cecilia de Araujo Rodrigues. Narrativas de uma coordenadora de um subprojeto PIBID de música: o PIBID como espaço formativo. In: VICENTINI, Paula Perin, CUNHA, Jorge Luiz da, CARDOSO, Lilian Auxiliadora Maciel (Org.). Experiências formativas e práticas de iniciação à docência. Curitiba: Editora CRV, 2016.

Recebido em 26/02/2019 - Aprovado em 14/03/2019

Como citar:

TORRES, M, C, A, R. (2019) Narrativas de uma professora de um curso de Licenciatura em Música: entrelaçando memórias e práticas musicais. OuvirOUver, 15(1), 72-84. https://doi.org/10.14393/OUV24-v15n1a2019-5

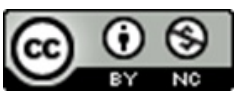

A revista ouvirOUver está licenciada com uma Licença Creative

Commons Atribuição-NãoComercial 4.0 Internacional. 